\title{
HOTS LEARNING IN PANDEMIC OF COVID-19 PERIOD THROUGH DEEP LEARNING MODEL
}

\author{
Heti Aisah ${ }^{1}$, Agus Salim Mansur'2, Qiqi Yulianti Zaqiyah ${ }^{3}$ \\ ${ }^{1}$ Educational Superintendent of West Java Province, Indonesia \\ 2,3UIN Sunan Gunung Djati Bandung, West Java, Indonesia \\ ${ }^{1}$ Contributor Email: Mihyusalsha@gmail.com
}

\begin{abstract}
Covid-19 pandemic has not shown a drastic decrease in trend, so it is estimated that the new school year 2020-2021 students will continue to carry out their learning processes from home, or Learning from Home. A survey conducted by the Ministry of Education and Culture's directorate's assessment department, related to Learning from Home students in March, showed that 29\% of students lack enthusiasm, 28\% thought it was normal, which stated Learning from Home was pleasant 26\%, 10\% burdensome, and 7\% others (boring, tiring, not communicative, not active). The condition needs to be sought a solution, one of the alternatives offered is the teacher or education unit using the strategy of learning activities Deep Learning. DEL is a process of learning activities that optimize and activate the work of the brain so that students do not experience boredom, and not excited. The final stage DEL is included in the domain of analysis and creates, allowing students to develop higher-order thinking skills or High Order Thinking Skills (HOTS).
\end{abstract}

Keywords: COVID-19, deep learning, HOTS

\section{A. Introduction}

The beginning of the new school year 2020-2021 most likely schools have not yet opened, and students are still carrying out learning activities at home or learning from home. This policy was issued as an effort to prevent the increasing spread of Coronavirus Disease-19 (Covid19), and to anticipate the second wave of the spread of Covid-19 in Indonesia. The case of school closure after a while opened, occurred in Korea, and France, the school closure was done after there was a case of 
students exposed to Covid-19. Learning from the case of the two countries, the Indonesian government in this case the Ministry of Education and Culture (Kemendikbud) took a pretty heavy policy, namely not yet allowing schools to carry out face-to-face learning, especially in areas that are still showing an increasing spread of Covid-19.

Information from the National COVID- 19 handling acceleration task force, in the third week of June (6/23) 2020, noted the addition of positive COVID-19 confirmed cases to 47,896 after an increase of 1,051 people. Then the patients recovered to 19,241 after there were an additional 506 people. Furthermore for the case of death to 2,535 with the addition of 35. This information illustrates that there are still additional cases of Covid-19 in Indonesia. This increase is predicted to continue to increase, since the Indonesian government imposed a new order or 'New Normal', because people assume that the new normal era is the same normalcy as before the Covid-19 pandemic, so they are ignorant of the Covid-19 protocol, which is civilizing live healthy and clean, wash hands, use masks, physical and social distancing.

The Government of Indonesia in March 2020 announced that Covid-19 had entered Indonesia, this announcement was followed up by the Ministry of Education and Culture by issuing a Minister of Education and Culture Circular No. 4 of 2020, which regulates the cancellation of the implementation of the National Examination, the implementation of learning activities at home or learning from home, the technical implementation of School Exams, the appeal not to face-to-face during the implementation of the assessment at the end of the year, to the strategy of accepting new student activities.

The Mendikbud circular made education practitioners in the education unit experience shock, in a short time, it was demanded to arrange an appropriate and enjoyable learning process for students to study at home. In urgent conditions, the education unit shifts direction in the learning process strategy, which was originally implemented face-to-face with students, there is direct interaction, into learning activities without face-toface, ie students learn from home. Even so, the results of an analysis of the results of a survey of learning from home during March of the high school level, conducted by the field of assessment of the directorate of the Ministry of Education and Culture High School, showed that 29\% of students lack enthusiasm, 28\% thought it was normal, which stated learning from home was fun $26 \%, 10 \%$ burdensome, and the other $7 \%$ (boring, tiring, non-communicative, inactive). 
The highest number of survey results is; $29 \%$ of students are not enthusiastic in implementing learning from home, the results are done when the teacher arranges plans in conditions that are not conducive. If the new school year learning from home is still being carried out, and even the trend will last for an odd semester, it is necessary to prepare and think about solutions to learning methods that allow students more enthusiasm in learning activities from home.

Deep Learning, is a model approach that encourages students to be more active and creative in thinking because each stage requires students to enter the level of knowledge ranging from factual to metacognitive stages, and the stages of the thought process that starts from knowing to creating. If seen from the stages, the DeL model can be chosen as one solution to increase the enthusiasm of students in Learning from Home activities.

\section{B. Method}

The approach used in this research is a qualitative approach using observation data collection techniques and documentary techniques, while the data analysis technique uses content analysis. The type of data used is secondary data. The study was conducted by identifying problems that occurred in learning activities during the co-19 pandemic, then the data were collected, analyzed, and concluded as needed which might be a solution to the problem in the form of a development strategy using library research.

\section{Finding and Discussion}

1. Teaching and Learning Activities during the Covid-19 Pandemic Period

Circular of the Minister of Education and Culture No. 4 of 2020, learning activities during the Covid-19 pandemic, carried out from home. Home Learning, Activities, carried out with the following provisions: a) Learning from Home through online/distance learning, is carried out to provide a meaningful learning experience for students, without being burdened with the demands of completing all curriculum achievements for grade and graduation; b) Learning from Home is focused on life skills education including the Covid-19 pandemic; c) the activities and learning tasks from home can vary 
between students, according to their interests and conditions, including considering the gap in access to learning facilities at home; d) Evidence or products Learning from Home are given qualitative and useful feedback from the teacher, without having to give quantitative scores.

Referring to the circular, the learning process activities while still in the Covid-19 pandemic, their activities were carried out from home. The learning objectives emphasize meaningful learning experiences (point a) and life skills education (point b). Both of these demands in the stages of the process of cognition, or the stage of gaining knowledge, have reached the stages of analyzing, evaluating, and even creating, and when viewed from the knowledge gained, students already have the skills to think metacognitively.

Learning from home allows students to reach the stage of acquiring meaningful learning and life skills. Learning that is not limited by time, allows more students to explore and develop the dimensions of the process of knowledge to the stage of the dimension of creating knowledge, or creating solutions to face life's challenges. Solutions that are created or found by students during learning from home, a basic provision in developing life skills.

Life skills are the ability and knowledge of a person to dare to face life's problems and to proactively seek and find solutions so that they are finally able to cope with the ability to interact and adapt to others, decision-making skills, problem-solving, critical thinking, creative thinking, effective communication, fostering interpersonal relationships, self-awareness, empathizing, overcoming emotions and coping with stress.

A variety of approaches, strategies, media and, methodologies can be used by the teacher in implementing learning activities from home, (point 3) giving the teacher the freedom to develop their pedagogical skills as a motivating teacher. This variation is in accordance with the condition of the students, both in terms of infrastructure or environmental support of students, especially parents/guardians of 
students. This point requires teachers to further develop their skills, knowledge, and fulfill pedagogical competencies.

Giving the value given by the teacher to students in the process of learning activities from home (point $\mathrm{d}$ ), is qualitative as a feedback or response to products made by students. In the 2013 curriculum, assessment emphasizes the assessment of feedback, as a positive response to the product of students, not merely measuring student learning outcomes (assessment of learning). Feedback assessment is more concerned with efforts so that students can improve their competence in the learning process, so the assessment approach places more emphasis on assessment as learning, in addition to the feedback assessment conducted by the teacher as an effort to make improvements to the learning process (assessment for learning). The third proportion of the assessment approach is seen in Figure 1.

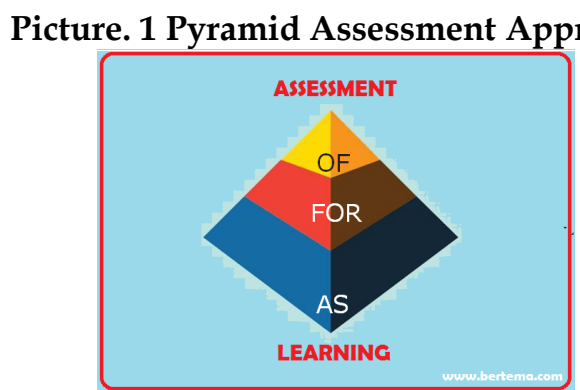

\section{HOTS Learning}

HOTS (Higher Order Thinking Skills), is a high-level thinking skill that is currently being applied to the learning process in all education units. HOTS learning is expected to be able to deliver students to fulfill

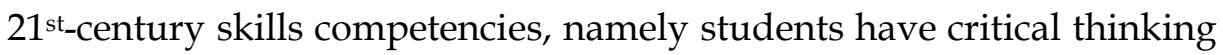
competencies; creative and innovative (creative and innovative); communication skills (communication skills); and the ability to work together (collaboration). This competency will be achieved if students have literacy competence and are supported by character education 
integrated into the learning process so that students are expected to have high self-confidence.

HOTS learning is closely related to thinking skills in accordance with the cognitive, affective, and psychomotor domains which are a unity in the learning process. The three domains were developed by Benjamin Bloom, in 1956, and are known as the Bloom concept. In the world of education, the concept continues to be used, until in 1990 the concept was improved by his students namely Lorin W. Anderson and David R. Krathwol, which was published in 2001. The cognitive domain includes the function of processing information, knowledge, and mentality skills. The affective domain includes functions related to attitudes and feelings. While the psychomotor domain is related to manipulative functions and physical abilities. Bloom's Taxonomic Revision, Anderson et al. revise it into two aspects: nouns and verbs to form separate dimensions. Nouns provide the basis for the dimensions of knowledge and verbs form the basis for the dimensions of cognitive processes.

Improvements made are changing Bloom's taxonomy from nouns to verbs. This is important because Bloom's taxonomy is a description of the thought process. It also carried out a shift in taxonomic order that illustrates from the low order thinking process to the high order thinking process. While still using nouns, learning orientation is on the product, even though learning is a process. Knowledge is the result of thinking not the process of thinking so that it is improved to remember which shows the lowest process. While creating is the highest level of thought process. This is very logical because new people can create when they can assess the strengths and weaknesses of something from various considerations and critical thinking. 
Table. 1 Stage of the Cognition Process and the difference between Bloom and Anderson

\begin{tabular}{|c|c|c|l|l|}
\hline $\begin{array}{c}\text { Ability } \\
\text { Level }\end{array}$ & $\begin{array}{c}\text { Deep } \\
\text { Cognitive } \\
\text { Level } \\
\text { composing } \\
\text { questions } \\
\text { Level1 }\end{array}$ & $\begin{array}{c}\text { Cognitive } \\
\text { Skill Level }\end{array}$ & $\begin{array}{c}\text { Bloom's } \\
\text { Taxonomy }\end{array}$ & $\begin{array}{c}\text { Revision of } \\
\text { Bloom } \\
\text { (Anderson, } \\
\text { Krathwohl) }\end{array}$ \\
\hline C1 & LOTS & Knowledge & Remember \\
\hline C2 & & & Understanding & Understand \\
\hline C3 & Level 2 & & Application & Apply \\
\hline C4 & Level 3 & HOTS & Analysis & Analyze \\
\hline C5 & & & Synthesis & Rate \\
\hline C6 & & & Assessment & Create \\
\hline
\end{tabular}

Anderson and Krathwol through the revised taxonomy have a series of processes that demonstrate cognitive complexity by adding dimensions of knowledge, such as factual knowledge, conceptual knowledge, procedural knowledge, and Metacognitive knowledge. To see the combination of the dimensions of knowledge and thought processes can be seen in the matrix below.

Table. 3 Combination of Knowledge Dimensions and Thinking Processes

\begin{tabular}{|c|c|c|c|c|c|c|c|}
\hline \multirow{6}{*}{ 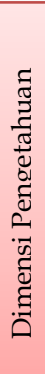 } & Metakonitif & Modify & Predict & Use & Destruct & Reflect & Create \\
\hline & Prosedural & Recall & Clarity & Carryout & Integrate & Judge & Design \\
\hline & Konseptual & Recognize & Classity & Provide & Differentiet & Determine & Assembly \\
\hline & Faktual & List & Summerize & Respond & Select & Check & Generate \\
\hline & & Mengingat & Memahami & Mengaplikasika & Menganalisa & Mengevaluasi & Mencipta \\
\hline & & \multicolumn{5}{|c|}{ Dimensi Proses Kognitif } & \\
\hline
\end{tabular}

The table above shows the position of HOTS learning will occur if students in the process of thinking are already at the stage of being able to analyze, evaluate to create. Whereas the dimension of knowledge 
obtained by students, when the dimension of knowledge gained knowledge, how the students were able to do Destruct, Reflect, and Create.

\section{Deep Learning}

Deep Learning is a set of student outcomes that includes mastery of important academic content; think critically and solve complex problems; work collaboratively and communicate effectively, and has an academic mindset, and is empowered through independent learning.

Morris further stated 6 strategies in deeper learning that need to be the teacher's attention in applying this model, namely: 1) Build and develop a strong learning community, by creating a more cohesive environment and truly collaborative building, combining high support and trust and collective responsibility for the continuity of learning. This can be done by inspiring students to care about each other's success; directing students to the value of learning and self-direction through various activities, messaging, and rituals; involving older students as mentors, models, and guides; establish norms for constructive learning feedback and reflection, and design buildings to reflect an environment that promotes openness and collaboration; 2) Empowering and activating students in leading learning independently. An active and meaningful educational experience is very important in helping students achieve their Deeper Learning goals. Like designing applications, organizing mock selection representatives from the selection process, or generating electricity by building wind turbines, schools that adhere to the Deep Learning objectives emphasize inquiry-based learning and keep students working actively and productively in groups to create products. or to solve shared problems. In this activity, the teacher must continually change roles, from curriculum design to advising to coaching to networking, and so on. 3) Contextual use of human themes proves that learning becomes more meaningful, with a deeper understanding of 
the material, when the material is personally relevant, and by integrating it in the subject. Subjects are not taught separately but instead learning is connected to a larger theme, by applying concepts from various subjects and applying learning to solve problems into actual problems through connectivity between subjects, 4) Reach or network extends beyond the walls of the school, helping to give learners a more holistic learning experience. As perfect networkers, teachers look for opportunities for students to utilize local resources such as museums and companies that are in line with school learning philosophy and students' interests and projects, produce broad support and learning networks for students, and help them explore potential career paths through an internship or mentorship, 5) Inspire by personalizing learning through a subject, idea, or project that makes students cheerful, is the key to a personalized learning experience for each student. To adapt learning to meet the educational needs and aspirations of each student, the teacher must seek and develop balanced knowledge about each student's unique trends, circumstances, and interests through formal (advisory) and informal processes (including ordinary conversation, insights from parents or other teachers), 6) Making technology as a media not the main benchmark in deep learning. Deeper learning when the use of technology aims to enhance learning, and as a medium to automate learning. This can be done in a number of ways, including using programs and applications that build students' research and critical thinking skills, offer digital methods to design projects, collaborate and communicate inside and outside of school, and expand student choices to present work creatively and connecting with many experts. In all cases, technology is used as a tool to encourage student learning.

Learning is a process of gaining knowledge, skills, attitudes, mental constructs, or values through study, experience, or teaching that causes a measurable change in the brain known as memory. Learning can be obtained through learning that is taught directly (explicitly) and obtained or obtained (implicitly) through life experience. In various ways, it allows learning to take place, but in terms of the impact 


\section{obtained, learning can be done simply and in-depth. For more details, it will be illustrated a table of differences and impacts obtained in simple learning and deep learning.}

Table. 4

\section{Differences between Simple Learning and Deeper Learning}

\begin{tabular}{|c|c|c|}
\hline & Simple Learning & Deeper Learning (Deeper Learning) \\
\hline Definition & $\begin{array}{l}\text { One-time learning, knowledge or } \\
\text { responses that can be learned by a } \\
\text { learner, does not require feedback or } \\
\text { error correction, can be learned in one } \\
\text { interaction and there is little or no } \\
\text { ambiguity }\end{array}$ & $\begin{array}{l}\text { Acquisition of new content or skills } \\
\text { that must be learned in more than } \\
\text { one step and by multilevel analysis } \\
\text { or processing, so that students can } \\
\text { apply content or skills in ways that } \\
\text { change thinking, influence or } \\
\text { behavior }\end{array}$ \\
\hline Pro & $\begin{array}{l}\text { Fast and simple, independent of age, } \\
\text { culture, IQ, generation and context, } \\
\text { provides familiarity and context, } \\
\text { serves as the basis for all future } \\
\text { learning mostly supports survival }\end{array}$ & $\begin{array}{l}\text { Many of the things that bring the } \\
\text { most satisfaction in life, come from } \\
\text { complex sets of skills and knowledge; } \\
\text { the brain can be activated more when } \\
\text { deeper learning occurs first; generally } \\
\text { their understanding, retention and } \\
\text { application are greater }\end{array}$ \\
\hline Counter & $\begin{array}{l}\text { Superficial knowledge, is a lesson that } \\
\text { can be obtained by children, do not } \\
\text { need to think much complicated, } \\
\text { learning can be done in the laboratory } \\
\text { and cannot be debated. }\end{array}$ & $\begin{array}{l}\text { Deep learning requires basic } \\
\text { background knowledge } \\
\text { (foundational), takes time, takes a lot } \\
\text { of effort and is determined to master } \\
\text { it; processes and end products are } \\
\text { often subject to critical review or } \\
\text { point of view }\end{array}$ \\
\hline Example & $\begin{array}{l}\text { Remember history, multiplication } \\
\text { tables, associations or the alphabet, } \\
\text { learn specific vocabulary and } \\
\text { definitions, learn people's names, } \\
\text { phone numbers, briefings or simple } \\
\text { activities }\end{array}$ & $\begin{array}{l}\text { Reading, multidisciplinary thinking, } \\
\text { solving problems by finding } \\
\text { solutions, creating goals and } \\
\text { strategies to achieve those goals; how } \\
\text { to negotiate, how to build something, } \\
\text { debate skills, research skills, } \\
\text { assemble, manage or do a } \\
\text { dissertation or job proposal }\end{array}$ \\
\hline Syn & $\begin{array}{l}\text { Responses that are conditioned, } \\
\text { unambiguous, single-step learning, } \\
\text { concise, one-sided, rote memorization, } \\
\text { associative learning, truncated baby } \\
\text { steps, isolated, essential }\end{array}$ & $\begin{array}{l}\text { Higher level thinking, complex } \\
\text { processing, multilevel abstract } \\
\text { thinking; divergent thinking, creative } \\
\text { thinking, critical thinking, multi-step } \\
\text { behavior, and procedural memory }\end{array}$ \\
\hline $\begin{array}{l}\text { Requirements and } \\
\text { educational } \\
\text { settings }\end{array}$ & $\begin{array}{l}\text { Requires external motivation, because } \\
\text { it rarely satisfies the needs for internal } \\
\text { encouragement, it may also impose it } \\
\text { on the learner to tend to be a more } \\
\text { localized brain activity taking place in } \\
\text { the brain versus a more distributive } \\
\text { learning }\end{array}$ & $\begin{array}{l}\text { Time, attention, background } \\
\text { knowledge (usually but not always), } \\
\text { specific processing procedures, there } \\
\text { is a tendency for more distributed, } \\
\text { ongoing brain activity in the brain } \\
\text { versus localized learning seen in } \\
\text { simple learning }\end{array}$ \\
\hline
\end{tabular}


The table of differences between simple learning and in-depth learning shows that simple learning when viewed from the level expressed in Bloom's taxonomic domain, is included in the LOTS strategy. Can be seen from the example of the achievement of the process of cognition, for example by giving examples, meaning that the achievement of cognitive is limited to remembering and understanding. Learning like this will cause boredom in students because it does not activate the brain optimally.

In the deep learning table, shows the learning process that requires students to have high thinking skills (HOTS). The process of achieving cognition, to the realm of analyzing, evaluating, and even creating. The brain is more activated to see the relationship of one component to another component. Critical thinking and absolute creativity are required in deep learning, and this condition motivates students to optimize their full potential, students are more motivated and enthusiastic in the learning process.

Eric Jensen explained that deep learning applies a 7 step cycle in the learning process, with the abbreviation DELC (deeper Learning Cycle). These steps are; 1) planning standards and curriculum; 2) preassessment; 3) building a positive learning culture; 4) priming (digging) and activating prior knowledge; 5) obtain new knowledge; 6) cultivate deeper learning, and 7) evaluate student learning. For more details, see the DELS step cycle picture. 


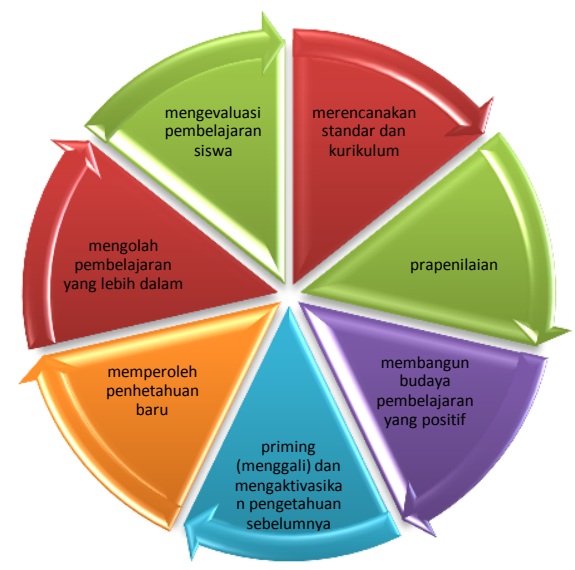

a.Steps for Planning Standards and Curriculum

The step in planning standards and curriculum is the first step that determines the success of deeper learners (deeper learning). This step can be done by identifying basic competencies in the standards that have been set, analyzing, and compiling learning objectives, approaches, strategies, and assessments to be carried out. This plan includes analyzing the basic competencies that support each other and are related to one another. This basic competency analysis can also collaborate with other subjects whose basic competencies are interrelated, and, so that in the implementation of learning becomes a collaborative work between subjects, which results in a product or project, or portfolio.

Graduation standards become a reference in planning school curriculum standards, in addition to content standards, process standards, and assessment standards. For education units planning curriculum standards so that in-depth learning can be carried out effectively and efficiently, it is necessary to consider infrastructure, funding, education, and education personnel, as well as the competencies of the leadership of the education unit itself.

Preparation of learning plans for Learning from Home activities needs to consider the environmental conditions of students, support from parents, and facilities owned by students. Basic competencies are chosen that enable students to comfortably implement Learning from Home, without reducing the creativity and innovation of students. Besides that, it is necessary to plan steps that can sharpen students' critical thinking. 


\section{b. Pre-assessment}

The Pre-assessment step in deep learning becomes a necessity, to know and understand the condition of students, both in terms of knowledge, skills, or attitudes. also, the teacher collects data on students 'potentials, for example, intelligence potential or (multiple intelligence), learning modalities, IQ, students' interests and talents.

Through this pre-assessment, the teacher better understands the ability and readiness of students in accepting the topic of the material to be delivered. Pre-assessment is a pre-test to determine the level of knowledge and understanding of students on the topic of the material to be delivered. The pre-assessment activities are carried out before the learning activities are carried out, the results being input for the teacher for the initial steps to give the topic material. In Learning from Home activities, the implementation of pre-assessment is more freely carried out by the teacher before entering the topic of the material to be delivered, for example, one week before learning, the teacher can pre-assess through the instruments given to the students.

c. Building a Positive Learning Culture;

Culture is the creation, maintenance, or modification of a unique body of ideas, customs, skills, language, and art from a person or group that is transferred, communicated or passed on Building a positive learning culture can be done by building relationships between teacherstudents. This relationship is a must in the development of a good learning process. Teachers who understand students' strengths, potentials, interests and talents, and intellectual abilities, are a basic capital in building a positive learning culture. This capital can help teachers choose what strategies will be used in the learning process. Trust felt by students towards the teacher becomes capital for the continuity of positive learning.

Building and strengthening teacher and student relationships can be done in a way; a) listen to students' stories, whatever is told as long as it is not personal; $b$ ) give learners inventories that ask questions about them, can be hobbies, or how they fill holidays and things related to asking them; c) greet them, or greet them when they meet or when they leave (go home). d) take time to talk with them, when they are resting, for example in the school canteen; e) there is no harm in telling the teacher about his hobbies, interests, or things that can dilute the rigid relationship between teachers and students $\mathrm{f}$ ) treat students as individuals who equally want appreciation. 
Building a positive learning culture can be done by maintaining relationships between students, through cooperative, collaborative learning. Teachers must be able to build cohesiveness between students, so that a positive learning culture will be built. Avoid grouping that can cause division or imbalance within the group. Building a passionate, motivated, and positive mind, important things are also considered in building a positive learning culture. Vesting (interest) is an emotional urge to learn. Humans have brains, based on design and function, allowing emotions to have a significant influence throughout most of our lives (Bechara, Damasio, \& Damasio, 2003). Emotion has always been found in widely accepted motivational theories. The self-determination theory (self-determination: SDT) has developed over the past 30 years and has also been validated by a broad research body (Ryan \& Deci, 2000).

Building a positive learning culture will affect the positive aura of students and teachers in deep learning activities. Positive aura will be seen and felt by students and teachers, such as the presence and overall mood of both parties (students and teachers), respect for interests, enjoyment, humor, and laughter, engagement, engagement, nonverbal behavior which is very influential, kinesthetic activity. Building a positive culture when Learning from Home can be done by the teacher by coordinating and collaborating with students' parents. Listening to students' stories, teachers can also do it through virtual communication or massage. Create an atmosphere that can motivate students not to feel bored or not even excited during Learning from Home

d. Priming and activating prior knowledge

Priming is an activity to explore and activate students' knowledge on the topic of the previous material, and as a bridge to continue the next material, a term is commonly known as Apperception. This step is carried out to activate prior knowledge, with the hope to a) increase opportunities in remembering the concepts and skills taught, b) strengthen connections and make content more relevant, c) ensure that prior knowledge is built with buffers, d) quickly correct Student misunderstanding or creating a plan to make corrections, e) encourage interest, motivation, as a greater opportunity towards success in learning. Priming can be done by providing a stimulus, through re-exposure to the topic of the previous material, and connecting with the material to be delivered. Presenting examples of material content. Exploring students' understanding with questions, or quis with material topics related to the previous material or material topics that will be delivered. 
Priming during Learning from Home, can be done by giving quizzes or small remote discussions. Quiz applications are widely available, which are easily accessed by students.

e. Acquire new knowledge

Learners gain new knowledge that can be done by taking one or two paths. First, new knowledge is obtained by learning and quality information that is dense and fast. Second, new knowledge is acquired all the time in bits and pieces, then becomes a lot. Knowledge obtained by students, information form, scope, amount, and so on, is processed and stored in the memory of students. At the time of priming, the teacher activates knowledge, information that has been obtained previously, as an introduction or bridging on new knowledge. If students in their memory do not store information or prior knowledge of material topics, then the teacher provides a stimulus with pieces of information and knowledge, or the teacher asks students to look for information from content that is trusted.

Strategies that can be done by the teacher in conveying new knowledge to be able to do priming (explore and apply prior knowledge), is to allocate time with a 10-80-10 timeline strategy. This means that $10 \%$ of the time is used to do priming, $80 \%$ of new knowledge learning, $10 \%$ after learning to consolidate or reflecting information knowledge that has been obtained by students. This closure can also be used to inform the topic of material that will be delivered at the next meeting. The step of gaining new knowledge at the time of Learning from Home will provide more opportunities for students. Time opportunities, which are not restricted as well as face to face in class. Long and flexible time opportunities give students the freedom to dig up more information through internet access, or observation in the lives of students at home.

f. Processing (Processing) deeper learning

Processing deeper learning emphasizes the response of the brain in transforming information obtained, into a consolidation, transformation, and internalization of information by students. The information becomes an understanding, insight, depth, and usefulness and as a byproduct to a memory. In the brain, processing transforms raw data into stored knowledge, meaning, experience, or feelings. The brain has channeled visual input, sound/sound, touch sensation, space representation. However, processing these levels does not give students a lot of cognitive sense, to obtain them, it takes useful strategies to move forward. Deep allows to involve almost all areas of the brain, because they involve the 
emotional, movement, spatial, language, sound, memory and thought fields in the brain.

Processing (Deep Learning) is done using several stages of the domain in the dimensions of cognitive processes. The domain of deep learning processing uses the DEEP model processing structure, each type of processing uses the term domain of thought, the teacher can arrange activities to be simpler with moderate or very challenging levels of difficulty. There are four domains in the process of deep learning, each domain serves a different purpose, but each other supports each other.

Information on the results of pre-assessment data and primings conducted previously, become a foothold in determining what domains will be applied to the process of deep learning processing. The domains referred to are the Awareness domain, the Analysis to Synthesis domain, the Application domain, the Assimilation domain.

Domain of Consciousness

The awareness domain prepares the brain to want more depth and breadth on topics that are just introduced or delivered. The result of this activity, students are in the status of awareness about interest and motivation to increase knowledge, awareness of prior knowledge is better understood, and the brain is better prepared to elaborate in more detail or more pieces of information. This domain as a starting point to improve other domains of deep learning.

Domain Analysis to Synthesis

Domain Analysis to Synthesis is done after students have gained awareness in the domain of awareness. Domain Analysis to Synthesis allows the brain to see the whole piece of knowledge, then create something new. The process of creating something new is done by contracting pieces of information that have been obtained, through sorting, then merging back into something new (create), in other words, student's analysis of information and then synthesize for deeper learning.

The teacher uses the Analysis to Synthesis domain to develop a single topic in broader and coherent details, students are asked to focus more on the details of the main ideas. If students do not focus on the main topic, then create questions that can bring students back to the top grade. This domain stage helps students understand the topic of new material, the product of this stage is the coherence and final wealth of understanding that can be explained by the words of the learner. Application Domain

This domain shows that students already understand the content of material topics or understand new knowledge, so that they are able to 
practice, apply, apply or use the information obtained so that it is beneficial to themselves, the environment and even benefit for all humans. The end product of this domain, students master content, by reproducing learning and being able to display the knowledge acquired in different ways from the start. Students can transform content to be more useful for themselves, so students can apply information and skills in various ways. The last step of this domain is that students can show what they are learning through a variety of products. Assimilation Domain The assimilation domain is the core of content, internalization of information in person, the existence of interpersonal connectivity with the content or skills acquired. This domain product makes students experience personal growth and change, eliminating habits and destructive patterns in the life cycle.

g. Evaluating Student Learning

Evaluating student learning is the final stage in deep learning, evaluation is very closely related to the achievement of the objectives of learning, which are formulated when the teacher prepares a learning plan. The learning objectives should ideally be set clearly, specifically on learning achievement. The goals are conveyed to students, verbally, or in writing. This message will be captured by the learner's brain, so the brain processes it and wants to know what it will look like at the end and its expectations. If the goal is delivered in the form of questions or quiz questions, then the brain responds and processes them to calculate the answer.

Writing the objectives of the final product of learning, it is endeavored not to use the word 'assessment', but to determine a product or result that shows the students' mastery of the content given. For example, the final results of a project, in the form of a report of results, the Republic, writing personal reflections, portfolio, or can be in the form of written instruments, in the form of quizzes, feedback, and others.

The Assessment covers three domains, namely attitudes, knowledge, and skills. These three domains have their characteristics in the process of evaluation activities. For knowledge content, you can use written or oral tests or assignments. Attitude assessment, done by observing the attitudes of students during the learning process, assessment among friends, and student self-assessment. while skills, evaluations are carried out on students' products, in the form of portfolios, projects, products, performance, practices, performance, etc. 


\section{E. Conclusion}

Deep Learning, is one choice that can answer the condition of the Covid-19 pandemic, where students do the learning process carried out from home. Concern that Learning from Home will result in a decline in the quality of learning of students, will not occur if the more specific education units of teachers prepare the content of learning material with strategic choices suitable for Learning from Home activities.

Deep in its stages can optimize the workings of the brain of students, so that the choice of Deep Learning strategies can answer the complaints of students during Learning from Home, which is not excited and responds to mediocre learning. The stages in deep learning encourage students to move towards satisfying the desires of the brain in processing information, processing to make a product. This process is related to the workings between thinking, feeling, and physiological.

Stages of work In-depth learning in the process of learning activities starting from the stages of awareness, analysis to synthesis, application, and assimilation, are the stages needed to develop higherorder thinking skills or High Order Thinking Skills (HOTS). Learning from Home uses a Deep Learning strategy, in line with the demands of the 2013 curriculum competencies, namely creative and innovative thinking competencies, critical thinking, building communication, and collaborative that are both virtual or massage. Digital literacy competencies will be further enhanced, as well as building an optimistic attitude, confidence, honesty, and responsibility. These competencies

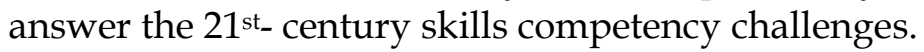

\section{Acknowledgment}

Armstrong Thomas, 2013, Multiple Intelligences in the Third Edition Class, Jakarta, PT Index.

Apandi Idris, 2018, Active Learning Strategies of the 21st Century and Hots, DI Yogyakarta, Samudra Biru

Ariyana Yoki, Ari Pudjiastuti, Reisky Bestary, Zamroni, 2018, Learning Handbook

Oriented at Higher Level Thinking Skills, Director General of GTK Kemendikbud.

Dr. Monica R. Martinez, 6 Powerful Strategies For Deeper Learning In Your Classroom, 6 Powerful Strategies For Deeper Learning In

Eric Jensen, LeAnn Nickelsen, 2011, Deeper Learning, Index, Jakarta Muchlisin Riadi Definition, Objectives and Types of Life Skills, Jan 62019 
Assessment Guide, 2017, Dirjen Dikdasmen Kemendikbud

Patilima Hamid, 2016, Qualitative Research Methods Revised Edition, Bandung, Alfabeta.

Permendikbud No. 28 of 2016, Quality Assurance System, Elementary Education

Rakhmat Jalaludin, 2006, Smart Learning, Bandung, Mizan Learning Center

Supardi, 2015, Effective School of Basic Concepts and Practices, Jakarta, PT Raja Grafindo Persada.

Suryana Yaya, 2015, Educational Management Research Methods, Bandung, Loyal Reader.

Yoki Ariyana, MT.dkk. 2018, Learning Handbook Oriented to HigherOrder Thinking Skills, Director General of GTK Kemendikbud.

Moh. Khoerul Anwar, Deep Learning to Shape Students' Characters as Learners, Teaching Journal and Tarbiyah Science 02 (2) (2017) 97104

Nur Fajriana Wahyu Ardiani, Nanda Adi Guna, Reni Novitasari, and Ridwan Prihantono, Thematic and Meaningful Learning in Bloom's Taxonomic Perspective, Satya Widya Journal, Vol. 29, No.2, December 2013: thematicAnderson.httpscore.ac.ukreader189005710.

https://www.kompas.com/edu/read/2020/05/29/152326971/setelahperancis-korsel-tutup-kembalidibuka?page=all

https://covid19.go.id/p/berita/update-konfirmasi-covid-19-pasiensembuh-meningkat-jadi-19241-positif-bertambah-1051-meninggalnaik-35-orang

ridwan202,

Taksonomi Anderson, https://ridwan202.wordpress.com/2014/03/19/taksonomuanderson/, 25 Juni 2020.

https://www.kajianpustaka.com/2019/01/pengertian-tujuan-dan-jeniskecakapan-hidup.html

https://www.google.com/search?q=piramida+pendekatan+penilaian 
https:// www.kompas.com/edu/read/2020/05/29/152326971/setelahperancis-korsel-tutup-kembali-250-sekolah-setelah-sempat dibuka?page=all 